\title{
Could multiple low-affinity bonds mediate primary sperm-zona pellucida binding?
}

\author{
Philip E. Castle \\ 4318 South 8th Street, Arlington, VA 22204, USA
}

\begin{abstract}
The current model for primary sperm binding to the zona pellucida is that a cell-surface sperm protein binds with high affinity in an order-specific manner to one of the zona pellucida proteins, ZP3. However, the molecular details of primary sperm-zona pellucida binding remain elusive. A possible revised model is that multiple low-affinity bonds between spermatozoa and the zona pellucida may be sufficient for primary binding. The avidity of several low-affinity bonds can exceed that of a single high-affinity bond, which is sufficient to tether a motile spermatozoon. A mechanism involving multiple low-affinity bonds could account for some of the difficulties in elucidating primary sperm-zona pellucida interactions.
\end{abstract}

In the early 1980s, Wassarman et al. published a series of seminal biochemical investigations on the mouse zona pellucida (Bleil and Wassarman, 1980; Bleil et al., 1981; Greve and Wassarman, 1985), the extracellular glycoprotein matrix that surrounds the mammalian egg, in which its protein constituents, ZP1, ZP2 and ZP3, were identified and named on the basis of molecular mobility on SDSPAGE gels. Furthermore, a model was developed for spermzona pellucida interactions. Capacitated spermatozoa, after reaching the oviduct, bind to the zona pellucida of ovulated eggs via an order-specific, high-affinity interaction between a sperm outer membrane protein and mouse ZP3. Binding triggers a sperm exocytotic event, the acrosome reaction, which leads to secondary binding between a sperm acrosomal membrane protein and mouse ZP2, and penetration of the zona pellucida. Mouse ZP1 is not involved directly in sperm-zona pellucida interactions but serves as a crosslinking protein for stability of the zona pellucida matrix. Subsequent studies demonstrated that monoclonal antibodies to mouse ZP2 and ZP3 could block fertilization in vivo, which strengthened the case for the functions attributed to these proteins (East et al., 1984, 1985).

A number of sperm proteins have been identified as candidates for primary binding to the zona pellucida. However, experimental genetic 'knock-out' or null models of these candidates in mice have failed to provide convincing evidence for any of these proteins as the primary zona-binding protein. For example, mice null for $\beta 1,4-$ galactosyltransferase (GalTase) have markedly reduced fertility, but fertility is not completely eliminated (Lu and Shur, 1997); the broad spectrum of negative physiological effects, including pituitary insufficiency and neonatal lethality, raises doubts as to whether the effects on fertility are direct or indirect (Lu et al., 1997). Genetic manipula-

Email:pc95p@nih.gov tions of mouse ZP3 have also been difficult to interpret. Mice null for ZP3 do not have a zona pellucida (Liu et al., 1996; Rankin et al., 1996). Genetic introduction of human ZP3 to mice null for mouse ZP3 restored the zona pellucida (chimaeric zona pellucida composed of human ZP3, mouse ZP3 and mouse ZP1) but did not change the phenotype of the mouse zona pellucida in that the chimaeric zona pellucida, like the wild-type mouse zona pellucida, bound mouse but not human spermatozoa (Rankin et al., 1998). The authors presented several hypotheses to explain this phenotype: (1) post-translational modification of human ZP3 with mouse-specific biological activity; (2) subtle alterations to the supramolecular structure of human ZP3 that favour mouse sperm binding; and (3) the requirement for a second human zona pellucida component for human sperm binding.

In light of these genetic experiments, an alternative mechanism for primary sperm-zona pellucida binding is proposed: sperm initially bind to the zona pellucida via multiple low-affinity bonds in the absence of a high-affinity receptor-ligand interaction. In the same way that decavalent immunoglobulin $M$ (IgM) can achieve avidity that approaches or exceeds that of bivalent IgG (Crothers and Metzger, 1972; Hornick and Karush, 1972; Roitt et al., 2001), the requisite avidity for binding between spermatozoa and the zona pellucida could be achieved via lowaffinity bonds. Baltz et al. (1988) demonstrated that one or a few non-covalent bonds with an affinity of a typical antibody-antigen interaction $\left(K_{\mathrm{A}} \approx 10^{6}-10^{10} \mathrm{M}^{-1}\right)$ were sufficient to 'tether' a spermatozoon. Upon binding, there is a large contact area between the spermatozoon and the zona pellucida as the spermatozoon appears to be bound not at the tip of the sperm head but rather at the flattened peri-equatorial region of the head; it is of note that antibodies to several antigens found in this region of the sperm head block sperm binding (Primakoff et al., 1985) 


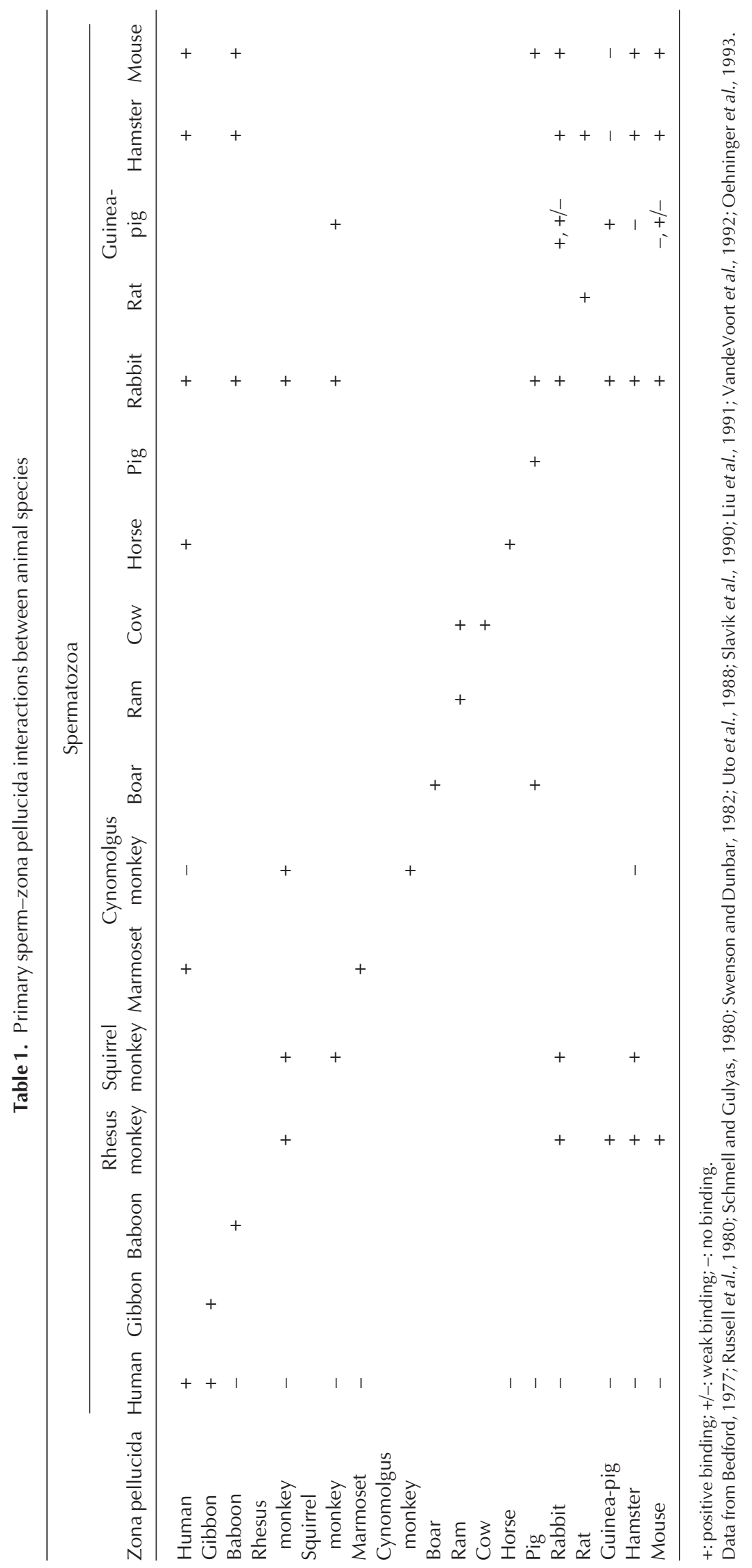


and fertility (Saling et al., 1983; Naz et al., 1984; Primakoff et al., 1988). Many low-affinity bonds could form a sufficiently strong bond, equivalent to a few high-affinity bonds needed for binding (Baltz and Cardullo, 1989), to tether spermatozoa temporarily, but could then yield to secondary interactions resulting in penetration of the zona pellucida by spermatozoa. If enough bonds formed rapidly, the torque developed from sperm motility would be unlikely to break such an interaction.

Is such a mechanism plausible? Given the logarithmic relationship between bond energy (strength) and affinity, several $10^{4} \mathrm{M}^{-1}$ 'weak' bonds will surpass the bond strength of a single $10^{10} \mathrm{M}^{-1}$ bond. A typical affinity bond is nothing more than a composite of weak interactions, such as ionic bonds, hydrogen bonds, Van der Waals interactions and hydrophobic interactions. In the extreme, these weak interactions need not be limited to a binding pocket, as envisioned by classical biochemistry, but could be spread across the interface between the spermatozoon and the zona pellucida. A requirement is that this mechanism must be sufficient to trigger the sperm acrosome reaction, which presumably is required for sperm penetration of the zona pellucida. Alternatively, a second high-affinity interaction could be responsible for triggering the acrosome reaction.

If the single components in the interaction are low affinity, they are unlikely to be specific and, contrary to current views, it might be expected that primary spermzona pellucida interactions are not order-specific. Indeed, cumulative evidence indicates that primary sperm-zona pellucida binding may not be highly order-specific (Table 1 and references therein), possibly with the exception of human spermatozoa, which appear to bind only to human and gibbon zonae pellucidae. The specificity of human spermatozoa appears to be the exception, not the rule, and may be the result of unique evolutionary pressures. For example, the environment of the human vagina is uniquely acidic and has a typical $\mathrm{pH}$ range of 3.5-4.5 (Boskey et al., 1999) compared with values of 5.9-7.0 (Johnson et al., 1984; Miller, 1994), 7.0 (Lichtenwalner et al., 2000), 5.5-6.0 (Johnson et al., 1984) and 7.0 (Johnson et al., 1984) for pig-tail macaques, rhesus macaques, chimpanzees and tamarins, respectively. Thus, to promote fertility, human spermatozoa may have adapted, and these changes, possibly to the sperm outer membrane, may inhibit interactions with heterologous zonae pellucidae. Unlike human spermatozoa, the human zona pellucida appears to be permissive to primary binding by heterologous spermatozoa.

In vitro zona-binding assays have been used to measure the inhibition of sperm binding by specific biochemical moieties. For example, Thaler and Cardullo (1996) and Johnston et al. (1998) demonstrated the inhibition of sperm binding by the addition of specific sugar moieties. It is noteworthy that $100 \%$ inhibition of binding was not achieved in either study. Moreover, the authors in each of these studies proposed specific sperm proteins involved in primary sperm-zona pellucida binding that either have not yet been proven to be important (fucosyltransferase) or may not even be found on the outer membrane (SP56; Foster et al., 1997). Neither study could differentiate between highaffinity bonds and multiple low-affinity bonds creating an equivalent avid bond. Thus, although both low- and highaffinity bonds may participate in binding, as suggested in both studies, high-affinity bonds may not be an absolute requirement for primary binding leading to fertilization. As suggested above, a second high-affinity sperm-zona pellucida interaction may be necessary for acrosomal activation.

\section{Conclusion}

The absence of confirmatory genetic data does not preclude the presence of one or several zona-binding proteins on the sperm outer membrane that bind with high affinity and specificity to ZP3. Indeed, a recent study has identified new sperm proteins that could invalidate a low-affinity, highavidity model, but the role of these proteins awaits further experimental confirmation (Thaler and Cardullo, 2002). However, these data also do not preclude an additional molecular mechanism of multiple low-affinity bonds that create sufficient avidity for sperm-zona pellucida binding and triggering of the acrosome reaction. It is possible that both mechanisms operate (Thaler and Cardullo, 1996; Johnston et al., 1998) and that the mechanism involving low-affinity bonds serves as a safety mechanism to ensure fertility. An example is the persistence of fertility in mice that are null for GalTase. It is possible that the ability of spermatozoa to undergo the acrosome reaction spontaneously is a further safeguard for fertilization. It is remarkable that the molecular details of primary binding remain elusive.

As a proposed alternative, this low-affinity, high-avidity mechanism is problematic because it is difficult to validate experimentally. Re-creating the molecular events with the correct molecular constituents involved in forming a single low-affinity bond is inherently challenging using standard molecular techniques. Should these moieties be identified, it is predicted that their ability to inhibit primary spermzona pellucida binding will be greatly enhanced by being displayed in two- and three-dimensional arrays that approximate the surfaces of the spermatozoon and the zona pellucida. A second prediction is that genetic knock-out of candidate sperm proteins will fail to eliminate completely primary binding, except in cases in which broad physiological changes occur as a consequence.

Results of recent genetic analyses have suggested that ZP2 and ZP3 evolve rapidly, which could explain the order specificity of sperm-zona pellucida interactions (Swanson et al., 2001). However, as mentioned above, primary binding does not appear to be highly order-specific. Furthermore, such a hypothesis would also indicate a parallel co-evolution of sperm proteins that would be required to maintain sperm-zona pellucida binding, which, to date, has not been identified. A less specific mechanism may be all that is required for primary sperm-zona pellucida binding, 
given the already substantial barriers to cross-fertilization between animal orders (O'Rand, 1988).

\section{References}

Key references are identified by asterisks.

Baltz JM and Cardullo RA (1989) On the number and rate of formation of sperm-zona bonds in the mouse Gamete Research 24 1-8

*Baltz JM, Katz DF and Cone RA (1988) Mechanics of sperm-egg interaction at the zona pellucida Biophysics Journal 54 643-654

*Bedford JM (1977) Sperm-egg interaction: the specificity of human spermatozoa Anatomy Record 188 477-487

Bleil JD and Wassarman PM (1980) Mammalian sperm-egg interaction: identification of a glycoprotein in mouse egg zonae pellucidae possessing receptor activity for sperm Cel/ 20 873-882

Bleil JD, Beall CF and Wassarman PM (1981) Mammalian sperm-egg interaction: fertilization of mouse eggs triggers modification of the major zona pellucida glycoprotein, ZP2 Developmental Biology 86 189-197

Boskey ER, Telsch KM, Whaley KJ, Moench TR and Cone RA (1999) Acid production by vaginal flora in vitro is consistent with the rate and extent of vaginal acidification Infection and Immunity 67 5170-5175

Crothers DM and Metzger H (1972) The influence of polyvalency on the binding properties of antibodies Immunochemistry 9 341-357

East IJ, Mattison DR and Dean J (1984) Monoclonal antibodies to the major protein of the murine zona pellucida: effects on fertilization and early development Developmental Biology 104 49-56

East IJ, Gulyas BJ and Dean J (1985) Monoclonal antibodies to the murine zona pellucida protein with sperm receptor activity: effects on fertilization and early development Developmental Biology 109 268-273

Foster JA, Friday BB, Maulit MT, Blobel C, Winfrey VP, Olson GE, Kim KS and Gerton GL (1997) AM67, a secretory component of the guinea pig sperm acrosomal matrix, is related to mouse sperm protein sp56 and the complement component 4-binding proteins Journal of Biological Chemistry $27212714-12722$

Greve JM and Wassarman PM (1985) Mouse egg extracellular coat is a matrix of interconnected filaments possessing a structural repeat Journal of Molecular Biology 181 253-264

*Hornick CL and Karush F (1972) Antibody affinity - III. The role of multivalence Immunochemistry 9 325-340

Johnson AP, Ison CA, Hetherington CM, Osborn MF, Southerton G, London WT, Easmon CS and Taylor-Robinson D (1984) A study of the susceptibility of three species of primate to vaginal colonization with Gardnerella vaginalis. British Journal of Experimental Pathology 65 389-396

Johnston DS, Wright WW, Shaper JH, Hokke CH, Van den Eijnden DH and Joziasse DH (1998) Murine sperm-zona binding: a fucosyl residue is required for a high affinity sperm-binding ligand. A second site on sperm binds a nonfucosylated, beta-galactosyl-capped oligosaccharide Journal of Biological Chemistry 273 1888-1895

Lichtenwalner AB, Patton DL, Klebanoff SJ, Headley $C M$ and Hillier SL (2000) Vaginal myeloperoxidase and flora in the pig-tailed macaque Journal of Medical Primatology 29 36-41

Liu C, Litscher ES, Mortillo S, Sakai Y, Kinloch RA, Stewart CL and Wassarman PM (1996) Targeted disruption of the mZP3 gene results in production of eggs lacking a zona pellucida and infertility in female mice Proceedings National Academy of Sciences USA 93 5431-5436

Liu DY, Lopata A, Pantke P and Baker HW (1991) Horse and marmoset monkey sperm bind to the zona pellucida of salt-stored human oocytes Fertility and Sterility $\mathbf{5 6}$ 764-767

Lu Q and Shur BD (1997) Sperm from beta 1,4-galactosyltransferase-null mice are refractory to ZP3-induced acrosome reactions and penetrate the zona pellucida poorly Development 124 4121-4131
Lu Q, Hasty P and Shur BD (1997) Targeted mutation in beta1,4 galactosyltransferase leads to pituitary insufficiency and neonatal lethality Developmental Biology 181 257-267

Miller CJ (1994) Use of the SIV/rhesus macaque system to test virucides designed to prevent the sexual transmission of HIV. In Barrier Contraceptives: Current Status and Future Prospects pp 213-224 Eds CK Mauck, M Codero, HL Gabelnick, JM Spieler and R Rivera. Wiley-Liss, New York

Naz RK, Alexander NJ, Isahakia M and Hamilton MS (1984) Monoclonal antibody to a human germ cell membrane glycoprotein that inhibits fertilization Science 225 342-344

Oehninger S, Mahony MC, Swanson JR and Hodgen GD (1993) The specificity of human spermatozoa-zona pellucida interaction under hemizona assay conditions Molecular Reproduction and Development 35 57-61

*O'Rand MG (1988) Sperm-egg recognition and barriers to interspecies fertilization Gamete Research 19 315-328

Primakoff P, Hyatt $\mathbf{H}$ and Myles DG (1985) A role for the migrating sperm surface antigen $\mathrm{PH}-20$ in guinea pig sperm binding to the egg zona pellucida Journal of Cell Biology $1012239-2244$

Primakoff P, Lathrop W, Woolman L, Cowan A and Myles D (1988) Fully effective contraception in male and female guinea pigs immunized with the sperm protein $\mathrm{PH}-20$ Nature 335 543-546

Rankin T, Familari M, Lee E, Ginsberg A, Dwyer N, Blanchette-Mackie J, Drago J, Westphal H and Dean J (1996) Mice homozygous for an insertional mutation in the Zp3 gene lack a zona pellucida and are infertile Development 122 2903-2910

*Rankin TL, Tong ZB, Castle PE, Lee E, Gore-Langton R, Nelson LM and Dean J (1998) Human ZP3 restores fertility in Zp3 null mice without affecting order-specific sperm binding Development 125 2415-2424

Roitt I, Brostoff J and Male D (2001) Immunology 6th Edn pp 72-73 Mosby, London

Russell LD, Peterson RN, Blumershine R and Freund M (1980) Morphological observations on the binding of boar sperm to porcine zona pellucida Scan Electron Microscopy 3 407-412

Saling PM, Raines LM and O'Rand MG (1983) Monoclonal antibody against mouse sperm blocks a specific event in the fertilization process Journal of Experimental Zoology 27 481-486

Schmell ED and Gulyas BJ (1980) Mammalian sperm-egg recognition and binding in vitro. I. Specificity of sperm interactions with live and fixed eggs in homologous and heterologous inseminations of hamster, mouse and guinea pig oocytes Biology of Reproduction 23 1075-1085

Slavik T, Pavlok A and Fulka J (1990) Penetration of intact bovine ova with ram sperm in vitro. Molecular Reproduction and Development 25 345-347

Swanson WI, Yang Z, Wolfner MF and Aquadro CF (2001) Positive Darwinian selection drives the evolution of several female reproductive proteins in mammals Proceedings National Academy of Sciences USA $982509-2514$

Swenson CE and Dunbar BS (1982) Specificity of sperm-zona interaction Journal of Experimental Zoology 219 97-104

Thaler CD and Cardullo RA (1996) Defining oligosaccharide specificity for initial sperm-zona pellucida adhesion in the mouse Molecular Reproduction and Development 45 535-546

Thaler CD and Cardullo RA (2002) Distinct membrane fractions from mouse sperm bind different zona pellucida glycoproteins Biology of Reproduction 66 65-69

Uto N, Yoshimatsu N, Lopata A and Yanagimachi R (1988) Zona-induced acrosome reaction of hamster spermatozoa Journal of Experimental Zoology 248 113-120

VandeVoort CA, Tollner TL and Overstreet JW (1992) Sperm-zona pellucida interaction in cynomolgus and rhesus macaques Journal of Andrology 13 428-432 